\title{
The cyclase-associated protein UvCap1 is required for mycelial growth and pathogenicity in the rice false smut fungus
}

\author{
Hui-Juan $\mathrm{Cao}^{1 \dagger}{ }^{\dagger}$ Jin-Jin Zhang $^{2+}{ }^{+}$, Ming-Li Yong ${ }^{1}$, Mi-Na Yu${ }^{1}$, Tian-Qiao Song ${ }^{1}$, Jun-Jie Yu', Xia-Yan Pan ${ }^{1}$ and \\ Yong-Feng Liu ${ }^{1,2^{*}}$
}

\begin{abstract}
Rice false smut caused by Ustilaginoidea virens is one of the widespread rice diseases across the globe in recent years, however, we know little about its molecular mechanism of infection. The cAMP signaling pathway functions directly in the development and formation of infectious structures to regulate the infection process in many pathogenic fungi. In order to investigate the role of the CAMP signaling pathway in U. virens, UvCap1, a cyclase-associated-protein homologous to Saccharomyces cerevisiae Srv2 was identified. Three targeted deletion mutants of the UVCAP1 gene were obtained with gene replacement strategy assisted with CRISPR-Cas9 system. The UVCAP1 deletion mutants showed defects in mycelial growth and conidial production. Inoculation experiments demonstrated that $\Delta U$ Uvcap 1 exhibited defects in pathogenicity. Compared with the wild-type strain, $\Delta$ Uvcap1 showed decreased tolerance to sorbitol and $\mathrm{H}_{2} \mathrm{O}_{2}$, and increased tolerance to $\mathrm{NaCl}, \mathrm{CFW}$ and SDS, and the intracellular CAMP level was significantly reduced in $\Delta$ Uvcap1. Yeast two-hybrid assay identified the interactions of UVCap1 with UvAc1 (adenylase cyclase), two Ras proteins (UvRas1 and UvRas2) and UvSte50. Taken together, as a component of cAMP signaling pathway, UvCap1 plays important roles in the development and pathogenicity of U. virens.
\end{abstract}

Keywords: Rice fungal disease, Ustilaginoidea virens, Cyclase-associated protein UvCap1, Mycelial growth, Pathogenicity

\section{Background}

Rice false smut has become one of the most prevalent fungal diseases of rice in recent years, and is currently seriously threatening food security (Zhou et al. 2008; Sun et al. 2020). This disease is caused by the ascomycete fungus Ustilaginoidea virens (Cooke) Takahashi (teleomorph: Villosiclava virens), which initially infects the stamen filaments and then extends to all floral organs of rice to produce false smut balls in spikelets (Tang et al. 2013; Song et al. 2016). The occurrence of rice false smut not only seriously affects the yield and quality of rice, but also produces a large number of

\footnotetext{
* Correspondence: liuyf@jaas.ac.cn

${ }^{\dagger} \mathrm{Hui}-\mathrm{Juan}$ Cao and Jin-Jin Zhang contributed equally to this work.

'Institute of Plant Protection, Jiangsu Academy of Agricultural Sciences, Nanjing 210014, China

${ }^{2}$ College of Plant Protection, Nanjing Agricultural University, Nanjing 210095, China
}

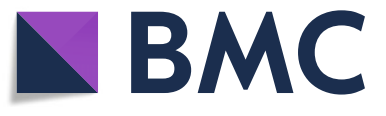

(- The Author(s). 2021 Open Access This article is licensed under a Creative Commons Attribution 4.0 International License, which permits use, sharing, adaptation, distribution and reproduction in any medium or format, as long as you give

appropriate credit to the original author(s) and the source, provide a link to the Creative Commons licence, and indicate if changes were made. The images or other third party material in this article are included in the article's Creative Commons licence, unless indicated otherwise in a credit line to the material. If material is not included in the article's Creative Commons licence and your intended use is not permitted by statutory regulation or exceeds the permitted use, you will need to obtain permission directly from the copyright holder. To view a copy of this licence, visit http://creativecommons.org/licenses/by/4.0/ (Tsukui et al. 2015). Therefore, there is an ongoing and urgent need for research into prevention of the disease. As a nonobligate biotrophic pathogenic fungus, the infection process of $U$. virens is significantly different from some other pathogenic fungi such as Magnaporthe oryzae. M. oryzae forms appressorium, a specialized infection structure that accumulates enormous turgor pressure to penetrate the host tissue (Talbot 2003). $U$. virens, in contrast, does not form specialized infection structures: after the mycelium penetrates the host epidermis, it cannot penetrate the plant cell wall and enter the host cell, but only grows in the intercellular space (Tang et al. 2013). Elucidating the unique infection mechanism of $U$. virens at the molecular level is of great theoretical significance for understanding the infection process of this fungus. 
The cAMP signaling pathway is essential for normal development of many eukaryotes. In plant pathogenic fungi, the conserved cAMP-PKA cascade regulates various developmental and infection processes (Adachi and Hamer 1998; Kang et al. 1999). Cyclase-associated proteins (CAPs), as important components of the cAMP signaling pathway, are well conserved in eukaryotes from yeast to humans (Hubberstey and Mottillo 2002). CAPs have been identified in Saccharomyces cerevisiae, Candida albicans, Cryptococus neoformans, Ustilago maydis and M. oryzae (Kawamukai et al. 1992; Rocha et al. 2001; Bahn et al. 2004; Zhou et al. 2012). In S. cerevisiae, a CAP gene named as $S R V 2$ was identified in the Rasresponsive adenylyl cyclase complex (Field et al. 1990; Mintzer and Field 1994; Yu et al. 1999). The N-terminus of Srv2 interacts with Ras2 and Cyr1 (adenylyl cyclase), and the C-terminus of Srv2 interacts with actin monomers (Quintero-Monzon et al. 2009). In C. albicans, Cap1 also interacts with adenylyl cyclase and Ras proteins to influence the intracellular cAMP level, and the CAP1 mutant is defective in bud-hypha transitions under specific environmental conditions (Bahn and Sundstrom 2001; Zou et al. 2010). In C. neoformans, the CAPs homologous protein Acal interacts with the Cterminus of adenylyl cyclase to regulate cell fusion, capsule formation and pathogenesis (Bahn et al. 2004). In $U$. maydis, Cap1 is an important component of the cAMP signaling pathway that interacts with adenylate cyclase Uac1 and regulates morphogenesis and pathogenesis (Takach and Gold 2010). In M. oryzae, CAP1 functions directly in the activation of adenylate cyclase, and regulates appressorium formation and plant infection. CAP1 is also involved in the feedback inhibition of the Ras2 signaling pathway in M. oryzae (Zhou et al. 2012). Although the cAMP signaling pathway is conserved and has essential functions in numerous plant pathogenic fungi, there is still no advancing research on CAP genes in $U$. virens.

In this study, we identified and characterized a CAPcoding gene, $U \nu C A P 1$, in $U$. virens. UvCap1 was found to interact with UvAc1, UvRas1, UvRas2 and UvSte50 in a yeast two-hybrid assay. $\Delta U \nu c a p 1$, the deletion mutant of $U \nu C A P 1$ was defective in mycelial growth, conidial production, some stress responses and pathogenicity. Collectively, our results demonstrate that UvCap1 plays important roles in the development and pathogenicity of the rice false smut fungus.

\section{Results}

Identification of CAP ortholog in U. virens

Srv2 is a CAP in the Ras-responsive adenylyl cyclase complex in the budding yeast $S$. cerevisiae (Yu et al. 1999). In this study, we identified UvCAP1 (KDB15885.1, UV8b_ $3197)$, a gene homologous to the yeast $S R V 2$ gene in the
$U$. virens genome by searching the National Center for Biotechnology Information (NCBI) database (accession number: GCA_000687475.1). UvCap1 was the only CAP ortholog we found in $U$. virens, and pfam analysis indicated that this protein contains two domains, CAP_N (11-377 aa) and CAP_C (399-557 aa) (Fig. 1a). A phylogenetic analysis of protein sequences showed that UvCap1 shares the highest similarity with the adenylate CAP from the filamentous fungi Claviceps purpurea (Fig. 1b).

\section{UvCap1 is required for mycelial growth and conidiation in} $U$. virens

To investigate the function of $U \nu C A P 1$ in $U$. virens, we generated the $U \nu C A P 1$ deletion mutant in the wild-type strain $\mathrm{P}-1$ by replacing the open reading frame (ORF) of UvCAP1 with the hygromycin resistance gene (HYG) through gene replacement strategy assisted with CRIS PR-Cas9 system (Liang et al. 2018). The replacement plasmid was created by homologous recombination (Additional file 1: Figure S1a) (Zheng et al. 2016), and the Cas9-gRNA vector was constructed as described previously (Liang et al. 2018). The resulting vectors were co-transformed into the protoplasts of strain P-1. HYGresistant transformants were first screened by PCR and further confirmed by sequencing. The results showed that the HYG gene replaced the ORF of UvCAP1 in $\triangle U v c a p 1$ (\#11, \#14 and \#29) (Additional file 1: Figure S1b). The copy number of HYG in $\Delta U v c a p 1$ (\#11, \#14 and \#29) was close to 1.0 , demonstrating that the $H Y G$ gene was inserted as a single copy. These three mutants showed similar phenotypic characteristics, so $\Delta U v$ cap 1 (\#11) was selected for subsequent study. The complemented transformants Uvcap1-c (\#1 and \#2) were obtained by complementing the $\Delta U \nu c a p 1$ (\#11) mutant with the $U \nu C A P 1$ gene driven by its native promoter, and were confirmed by RT-PCR and phenotypic analysis (Additional file 1: Figure S1c).

To explore if UvCap1 is involved in mycelial growth and colony morphology in $U$. virens, the wild-type strain $\mathrm{P}-1$, the mutant strains $\Delta U v$ cap $1(\# 11, \# 14)$ and the complemented strain Uvcap1-c (\#1) were cultured on PSA and TB3 medium plates for 20 days. $\Delta U v$ cap1 (\#11, \#14) had a reduced mycelial growth compared with those of P-1 and Uvcap1-c (\#1) (Fig. 2a, b). On PSA plate, the average colony diameter for P-1 was $47.6 \mathrm{~mm}$, while those for $\Delta U v c a p 1$ (\#11) and $\Delta U v c a p 1$ (\#14) were $23.4 \mathrm{~mm}$ and $24.0 \mathrm{~mm}$, respectively. The colony sizes of $\Delta$ Uvcap1 (\#11, \#14) in PSB were also significantly smaller than those of P-1 and Uvcap1-c (\#1) (Fig. 2a, b). There was no significant difference in conidial morphology between $\Delta U v c a p 1$ (\#11, \#14) and P-1, however, $\Delta U v \operatorname{cap} 1$ (\#11, \#14) produced significantly fewer conidia than P-1, with $\Delta U v$ cap1 (\#11, \#14) having only $28-35 \%$ of the number of conidia produced by P-1 (Fig. 2c). In 


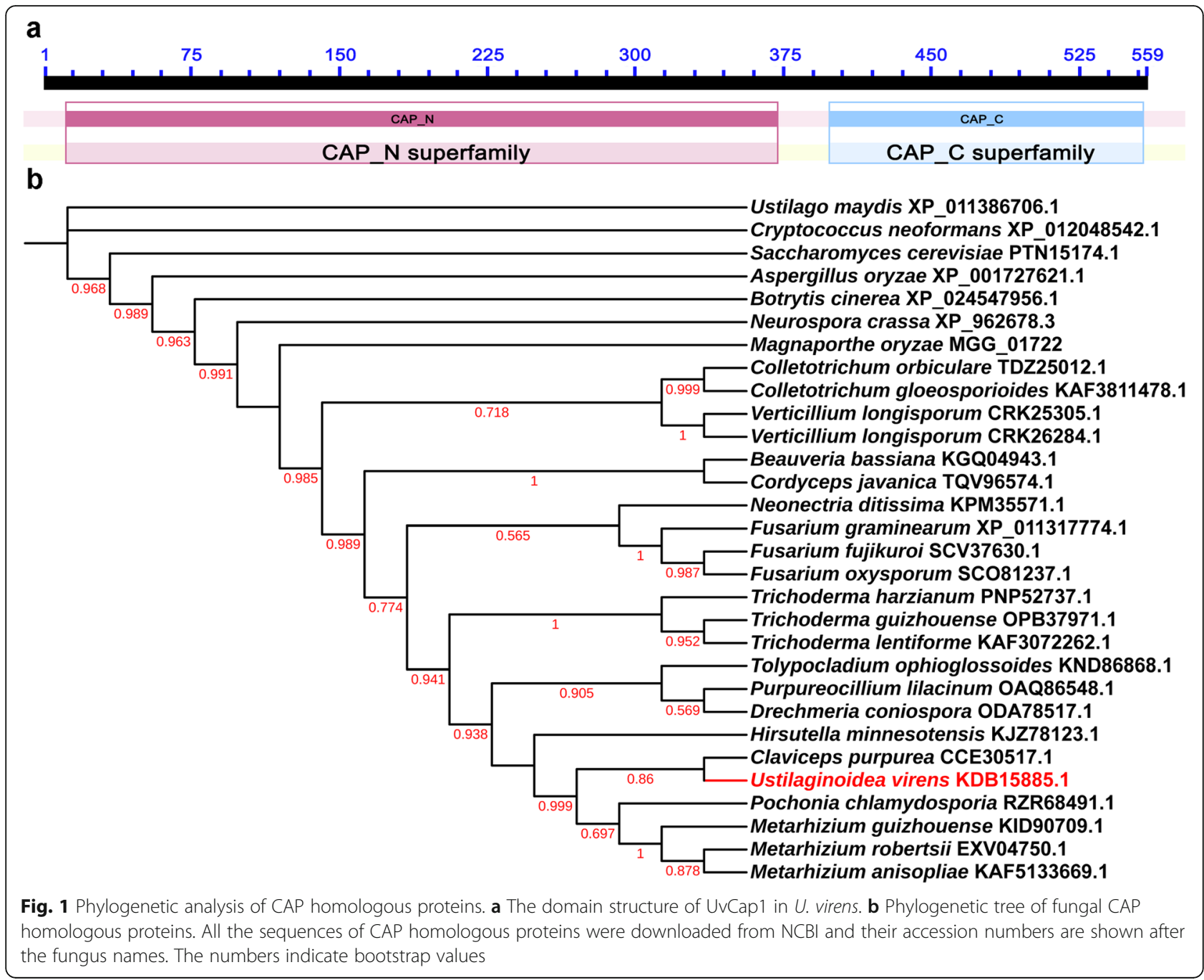

Uvcap1-c (\#1), the defects in growth and conidiation were restored to the level of the wild-type strain (Fig. 2). These results indicate that UvCap1 is required for mycelial growth and conidial production in $U$. virens.

UvCap1 is required for full virulence of $U$. virens

We next investigated the role of UvCap1 in regulating the virulence of $U$. virens. Suspensions of shattered hyphae and conidia from P-1, $\Delta U v \operatorname{cap} 1$ (\#11) and Uvcap1$c(\# 1)$ were inoculated into Liangyoupeijiu panicles at booting stage (5-7 days before heading). At 30 days post inoculation ( $\mathrm{dpi}$ ), the false smut balls produced on rice panicles were counted to evaluate the virulence of the inoculated strains. The average number of false smut balls per panicle for P-1, Uvcap1-c (\#1) and $\Delta U$ vcap1 (\#11) were 26.5, 27.3 and 19.0, respectively (Fig. 3a, b). Additionally, mycelial expansion of these strains inside the spikelets of rice was observed at 10, 14 and $18 \mathrm{dpi}$, and the results demonstrated that mycelial expansion was slower in spikelets inoculated with $\Delta U \nu$ cap1 (\#11) than with P-1 and Uvcap1-c (\#1) (Fig. 3c). To further observe the difference in the infection process, $\mathrm{P}-1, \Delta U \nu$ cap1 (\#11) and Uvcap1-c1 (\#1) were tagged with GFP, and used to inoculate rice plants. Results of fluorescence microscopic examination showed that there were fewer GFP-tagged hyphae inside the spikelets infected by $\Delta U \nu$ cap1 (\#11) than by the wild-type and complemented strains (Fig. 3d). These results indicate that UvCap1 affects the growth of infection hyphae to regulate the pathogenicity of $U$. virens.

UvCap1 regulates stress responses in $U$. virens

The cAMP signaling pathway is essential in sensing and response to changes of extracellular environments. $\Delta U v a c 1$ shows increased tolerance to sodium chloride $(\mathrm{NaCl})$ and decreased tolerance to Congo red (CR) (Guo et al. 2019). Here we investigated if UvCap1 is involved in responses of $U$. virens to osmotic, oxidative and cell wall stresses. The wild-type strain $\mathrm{P}-1$, the $\Delta U$ vcap 1 (\#11) mutant and its complemented strain Uvcap1-c 


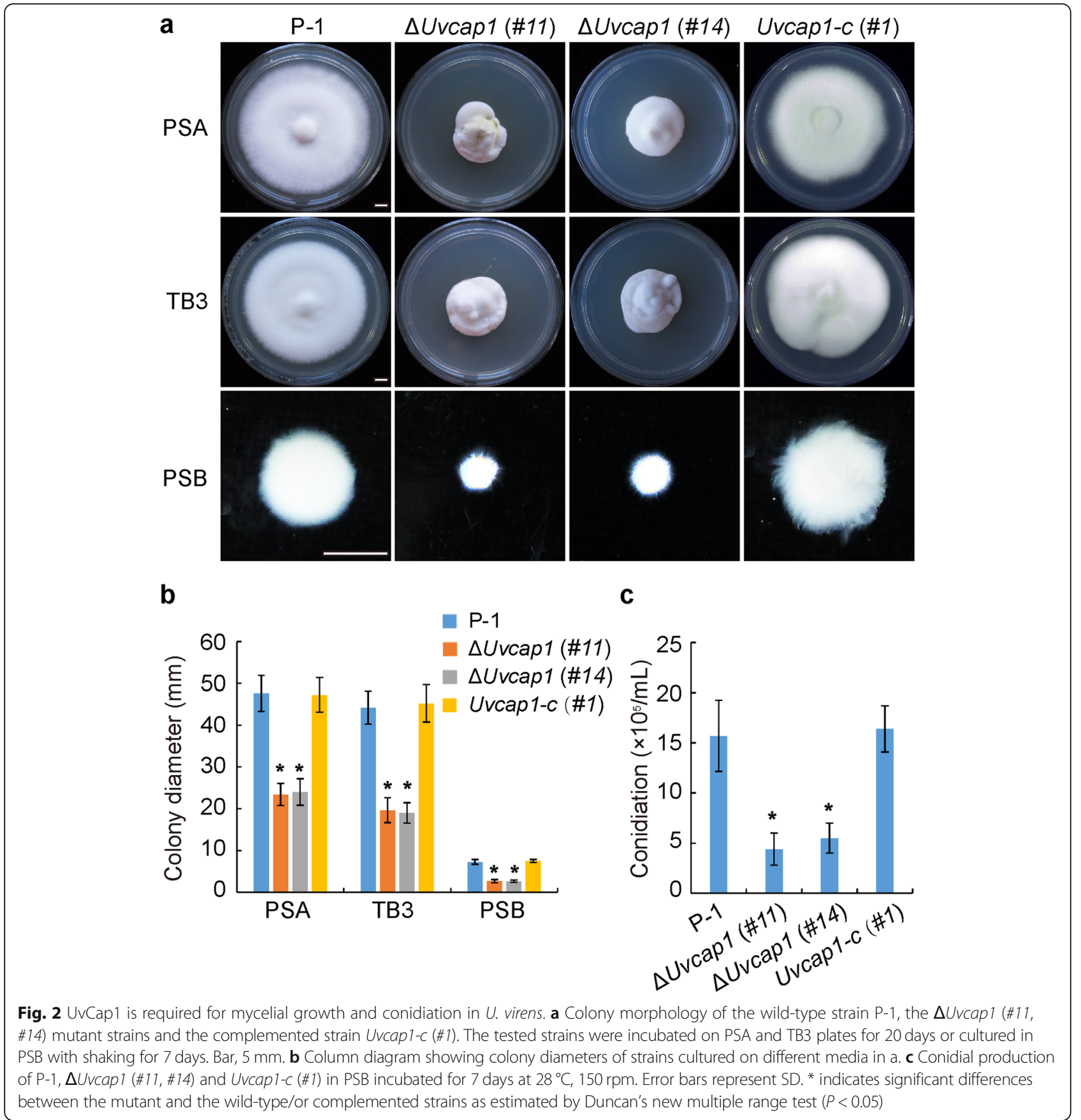

(\#1) were cultured on PSA medium plate supplemented with different stress agents. Compared with P-1 and Uvcap1-c (\#1), the growth inhibition rate of $\Delta U \nu$ cap1 (\#11) was significantly different. Under $0.6 \mathrm{M}$ sorbitol and $0.05 \% \mathrm{H}_{2} \mathrm{O}_{2}$ treatment, $\Delta U v$ capl (\#11) showed decreased tolerance (Fig. 4a, b). $\Delta U v$ cap1 (\#11) exhibited increased tolerance to $0.5 \mathrm{M} \mathrm{NaCl}, 500 \mu \mathrm{g} / \mathrm{mL}$ CFW and $0.05 \%$ SDS. On PSA medium plate with $100 \mu \mathrm{g} / \mathrm{mL}$ Congo red (CR), the growth inhibition rate of $\Delta U v c a p 1$ (\#11) showed no difference from P-1 and Uvcap1-c (\#1)
(Fig. 4a, b). These results suggest that UvCap1 is required for regulating the responses of $U$. virens to osmotic, oxidative and cell wall stresses.

\section{UvCAP1 was highly expressed during the early infection} stage of $U$. virens

According to previous studies on the infection process of $U$. virens, conidia germinate to form hyphae to extend to the interior of spikelets through the gap between lemma and palea at 1-2 dpi. The hyphae then infect 

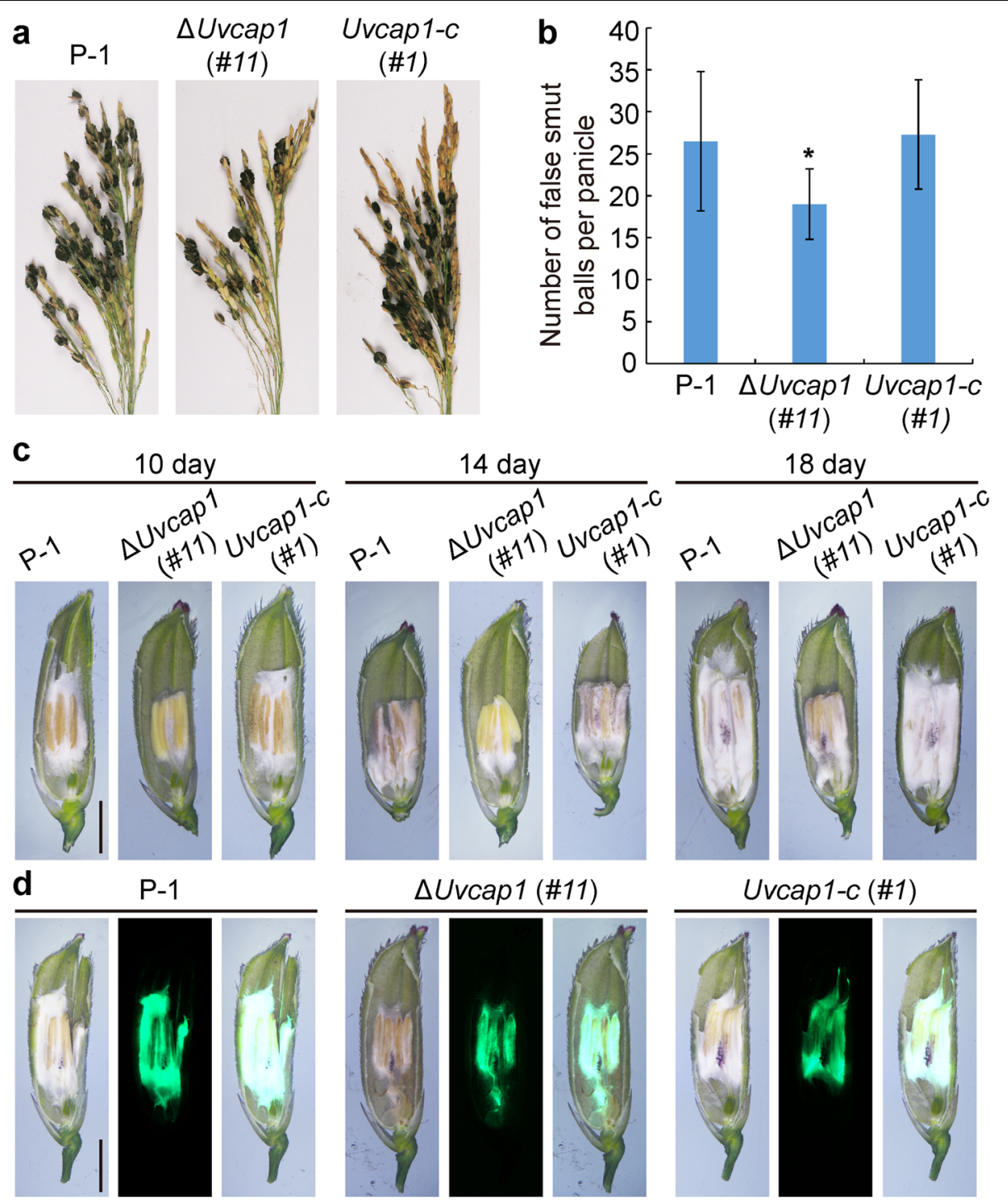

Fig. 3 UvCap1 is required for full virulence of U. virens. a The rice false smut balls generated by the wild-type strain P-1, the $\Delta U$ Vcap 1 (\#11) mutant and its complemented strain Uvcap 1-c (\#1). Pictures were taken at 30 dpi. b Column diagram showing the average numbers of false smut balls in an infected panicle in a. Error bars represent SD. * indicates significant differences between the mutant and the wild-type/or complemented strains as estimated by Duncan's new multiple range test $(P<0.05)$. c Mycelial extension of P-1, $\Delta$ Uvcap 1 (\#11) and Uvcap1-c (\#1) inside the spikelets at 10, 14 and 18 dpi. Bar, $10 \mu \mathrm{m}$. d Mycelial extension of GFP-tagged P-1, $\Delta$ Uvcap 1 (\#11) and Uvcap 1-c (\#1) inside the spikelets at $10 \mathrm{dpi}$. Bar, $10 \mu \mathrm{m}$

flower organs including filaments, anthers and stigma at 3-7 dpi, and fungal mycelia develop quickly and enclose the entire flower organs, filling the whole spikelets by $8-$ 15 dpi (Song et al. 2016). In order to gain a deeper understanding of the function of $U \nu C A P 1$ in the pathogenicity of $U$. virens, RT-qPCR was used to detect the relative expression level of $U \nu C A P 1$ during the infection process of $U$. virens. The inoculated rice spikelets at 0,1 , 2, 3, 5, 7 and 14 dpi were collected for RT-qPCR assay. The results showed that the expression level of $U \nu C A P 1$ had an upward trend at the initial stage of inoculation, reaching the highest value at $3 \mathrm{dpi}$, which was 5.14 times the expression level at the time of initial inoculation
(Fig. 5). After that, the expression level of the gene showed a downward trend (Fig. 5).

UvCap1 interacts with UvAc1, Ras proteins and UvSte50 Previous studies found that the CAPs function as a component of the cAMP signaling pathway, interacting with adenylate cyclase and regulating morphogenesis and pathogenesis (Bahn et al. 2004; Quintero-Monzon et al. 2009; Takach and Gold 2010; Zou et al. 2010; Zhou et al. 2012). In S. cerevisiae and C. albicans, Cap1 interacts with Ras and adenylyl cyclase proteins (Quintero-Monzon et al. 2009; Zou et al. 2010). In U. maydis and M. oryzae, Cap1 interacts with adenylate cyclase to positively regulate 


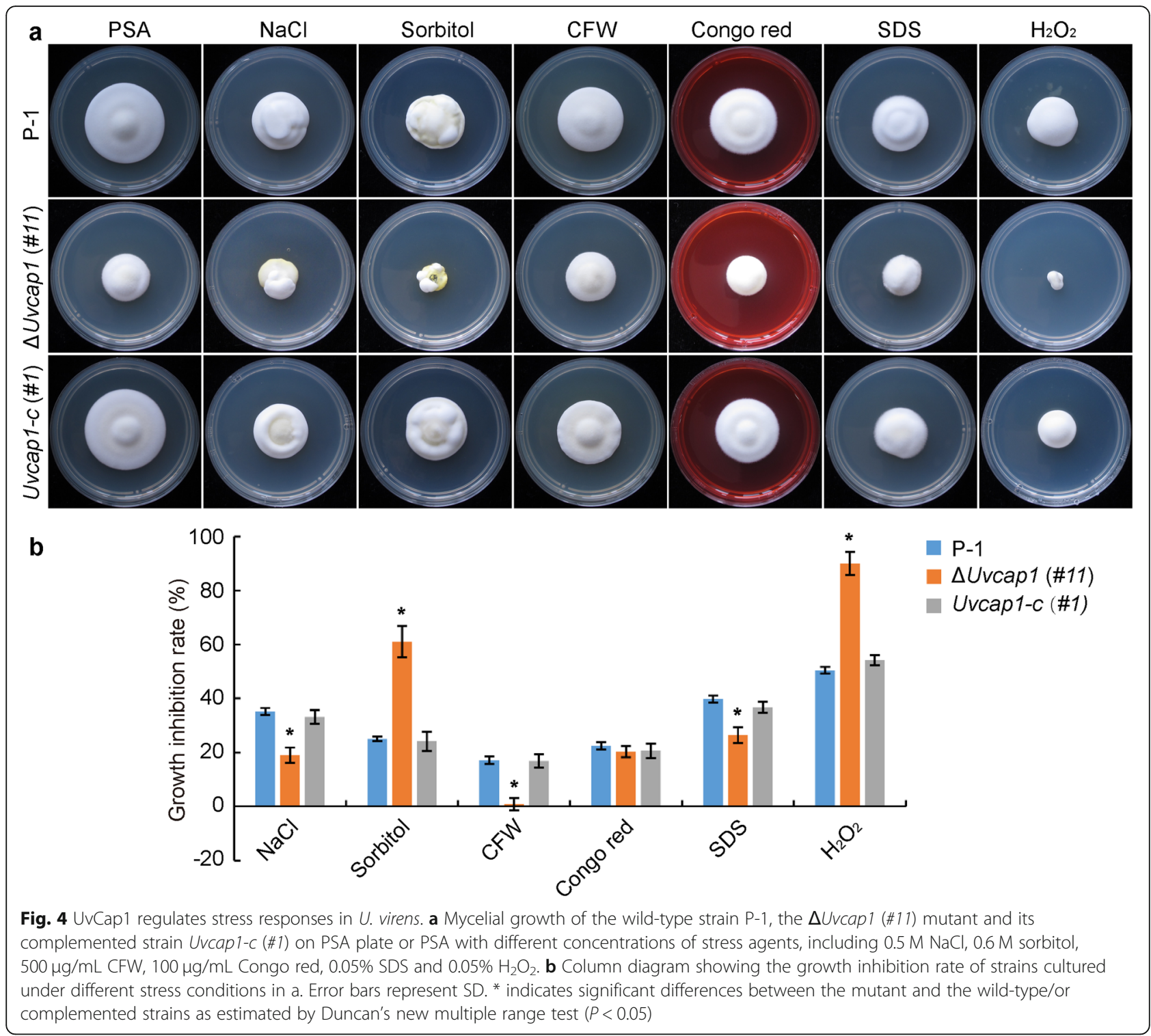

adenylyl cyclase (Takach and Gold 2010; Zhou et al. 2012). Here, we used yeast two-hybrid assays to identify the interactions of UvCap1 with UvAc1, Ras proteins $(U$. virens has two Ras proteins in the genome database) and UvSte50. The results showed that UvCap1 interacts with UvAc1 (the C-terminal region), UvRas1, UvRas2 and UvSte50 (Fig. 6).

\section{UvCap1 affects the intracellular cAMP level in U. virens}

cAMP is a ubiquitous second messenger that plays a critical role in the activation of downstream pathways in both eukaryotic and prokaryotic cells. cAMP is produced from ATP by adenylate cyclase and the intracellular cAMP level is significantly decreased (17.0-fold) in the $\Delta$ Uvac1 mutant (Guo et al. 2019). Here we assayed the cAMP level in the wild-type strain P-1, the $\Delta U v$ cap 1
(\#11) mutant and its complemented strain Uvcap1-c (\#1). Compared with that in P-1, the intracellular cAMP content in $\triangle U v$ cap1 (\#11) was significantly reduced (2.0fold) (Fig. 7). These results indicate that just like UvAc1, UvCap1 plays an important role in maintaining the intracellular cAMP level in $U$. virens.

\section{UvCap1 was distributed as spots in the cytoplasm of hyphae and conidia}

In order to explain the possible role of UvCap1 in $U$. virens, a subcellular localization assay was carried out. The UvCap1:GFP transformant was observed using a confocal laser scanning microscope (CLSM). UvCap1 showed strong fluorescence signals as spots in the cytoplasm of hyphae (especially in the apical regions of hyphae) and conidia (Fig. 8a, b). The distribution of 


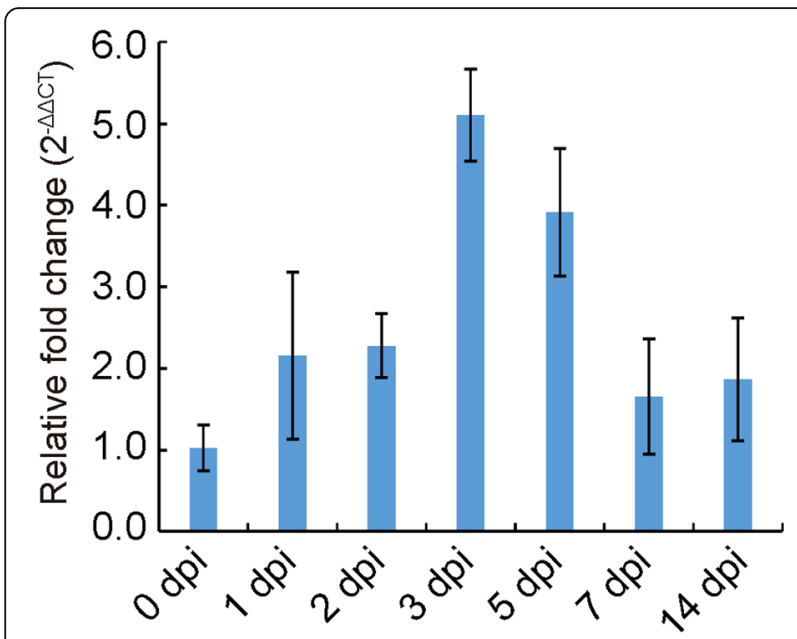

Fig. 5 Expression pattern of UVCAP1 during the infection process of $U$. virens. The inoculated panicle at 0, 1, 2, 3, 5, 7 and 14 dpi were collected to detect the expression level of UVCAP1. RT-qPCR was performed with five biological replicates; $\beta$-TUBULIN gene was used as the reference gene. Error bars represent SD
UvCap1 in hypha of $U$. virens was similar to that of Cap1 in M. oryzae (Zhou et al. 2012). Western blot analysis was performed to detect UvCap1 expression in the UvCap1:GFP transformant. UvCap1:GFP showed a 86$\mathrm{kDa}$ band against the anti-GFP antibody, which is consistent with the protein size of UvCap1 fused with GFP (Fig. 8c). The results suggest that UvCap1 is constitutively expressed in the cytoplasm.

\section{Discussion}

In this study, the PEG-mediated transformation and CRISPR/Cas9-based targeted gene replacement method was used to obtain the $U \nu C A P 1$ gene deletion mutants. The CRISPR/Cas9 system significantly promoted gene replacement frequency in $U$. virens as previously reported by Liang et al. (2018).

CAPs are involved in regulating the development and pathogenesis of many pathogenic fungi. In human pathogens, the mutant of $A C A 1$ (homologous to CAPs) in Cryptococcus neoformans and the CAP1 mutant in Candida albicans are non-pathogenic (Bahn and Sundstrom 2001; Bahn et al. 2004). In M. oryzae, the $\Delta$ cap1 mutant has defects in invasive growth in host cells, so lesions

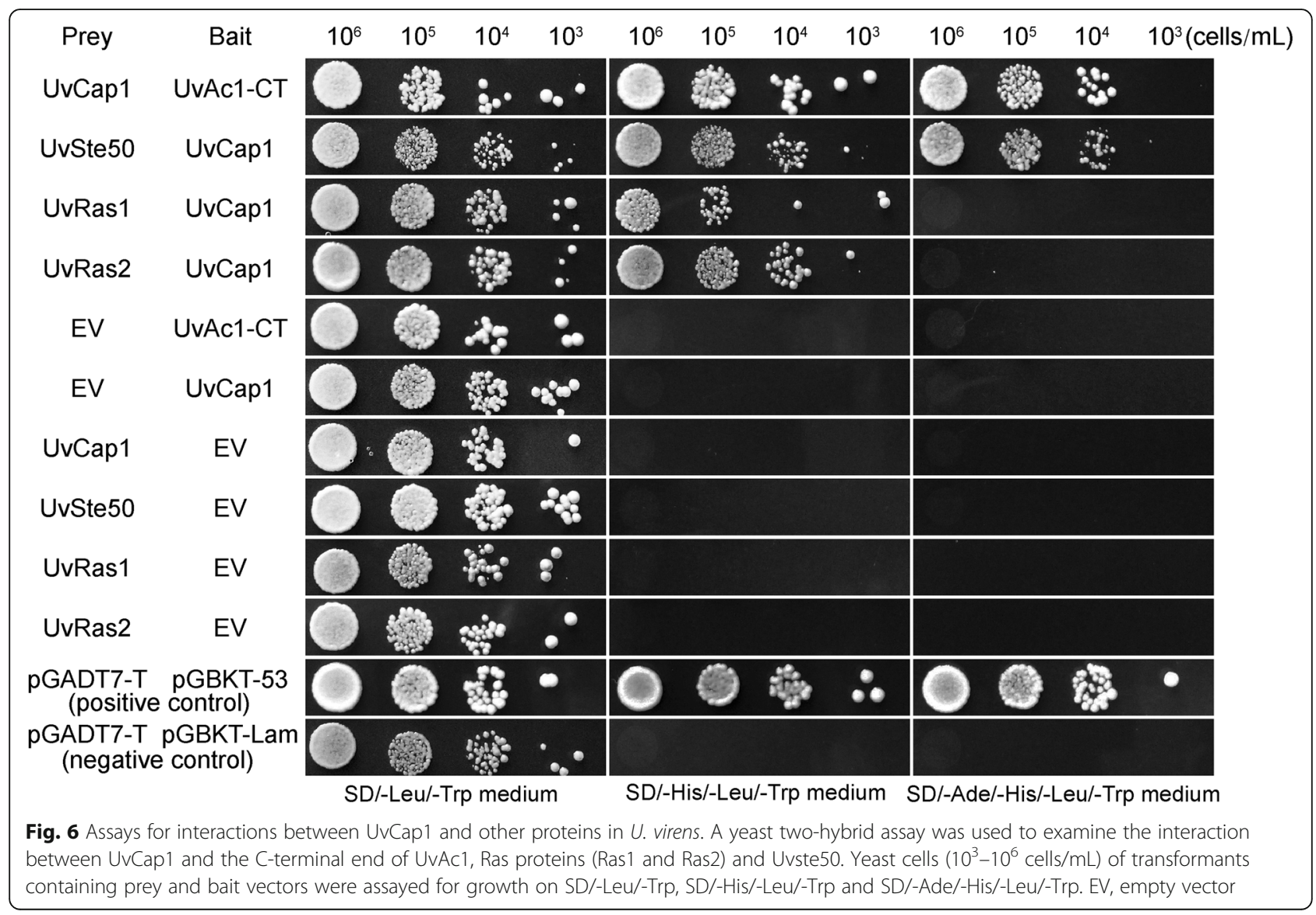




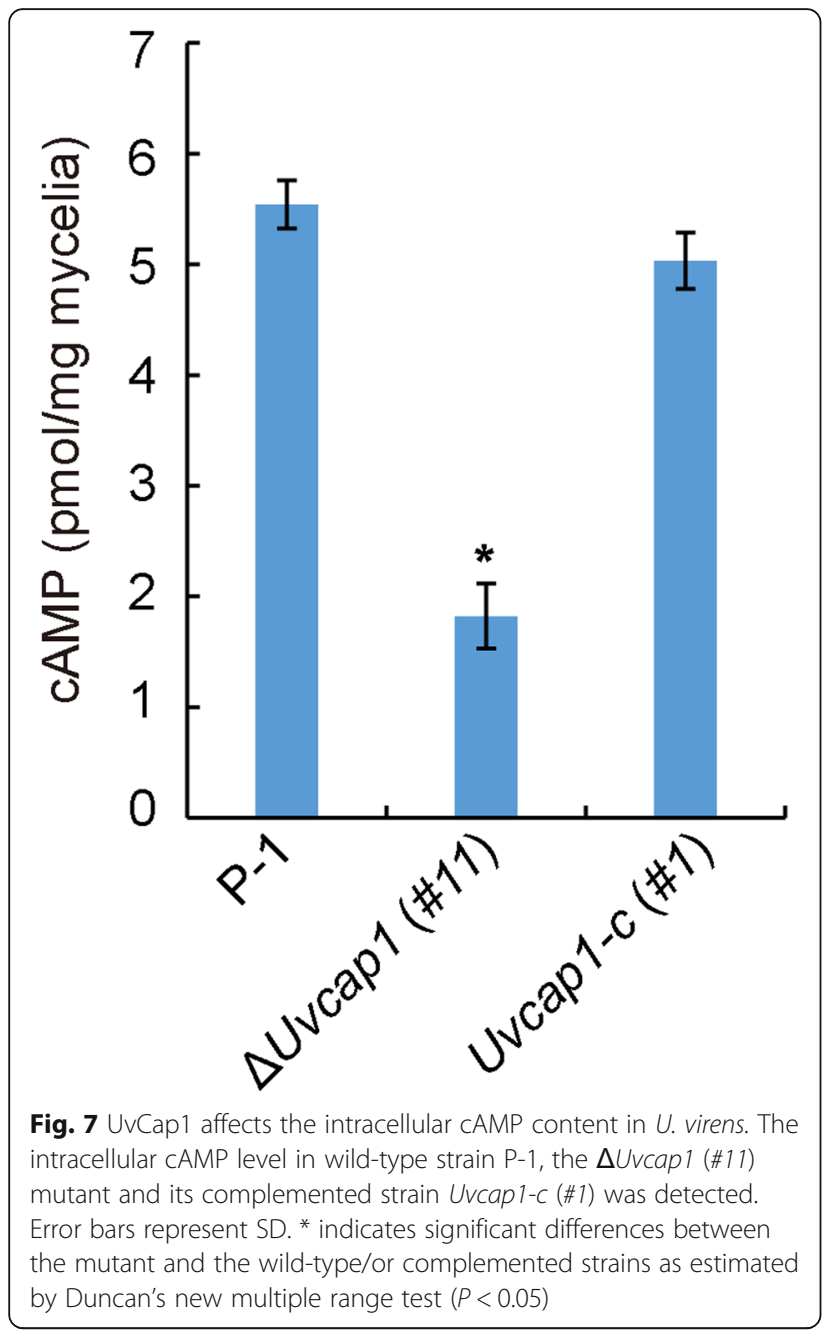

caused by this mutant are significantly reduced compared with those by the wild-type strain (Zhou et al. 2012). Adenylate cyclase UvAc1 functions directly in the infection process of $U$. virens: the $\Delta U v a c 1$ mutant cannot form false smut balls on rice panicles (Guo et al. 2019). Our results showed that UvCap1 is required for full virulence of $U$. virens (Fig. 3). Compared with $\Delta U v a c 1, \Delta U v c a p 1$ had a much milder effect on the virulence of $U$. virens to rice. In the early stage of infection, the growth of infection hyphae of $\Delta U \nu$ cap 1 in the diseased spikelets was slower than that of the wild-type strain, and the number of false smut balls produced by $\Delta U \nu c a p 1$ was reduced (Fig. 3). $\Delta U \nu c a p 1$ showed serious defects in mycelial growth and conidiation (Fig. 2). UvCap1 is also required for regulating the responses of $U$. virens to multiple stresses; $\Delta U v$ vap1 showed increased tolerance to $\mathrm{NaCl}, \mathrm{CFW}$ and SDS, and decreased tolerance to $\mathrm{H}_{2} \mathrm{O}_{2}$ and sorbitol (Fig. 4). UvCap1 thus has regulatory roles in the development and infection process of $U$. virens.

The localization of CAPs varies slightly in different organisms at different developmental stages. In yeast, CAP/Srv2p is located in cortical actin patches to regulate the cytoskeleton ( $\mathrm{Yu}$ et al. 1999). In Dictyostelium discoideum, CAP is distributed throughout the cytoplasm and shows enrichment at plasma membrane regions (Gottwald et al. 1996; Noegel et al. 1999). In mouse, Cap1 is widely present in nonmuscle cells, while Cap2 is mainly present in developing striated muscles. Cap1 colocalizes with cofilin-1 to dynamic regions of the cortical actin cytoskeleton in cultured NIH3T3 and B16F1 cells (Bertling et al. 2004). Cap1, as an actin shuttle, provides a link from actin cytoskeleton to mitochondria, and in cells induced for apoptosis, Cap1 is rapidly translocated to the mitochondria (Wang et al. 2008). In $M$. oryzae, Cap1 also has an actin-like localization pattern in hyphae and germ tubes (Zhou et al. 2012). In $U$. virens, the strain UvCap1:GFP showed strong GFP signals as spots in the cytoplasm of the hyphae (especially in the apical regions of hyphae) and conidia (Fig. 8a, b). Whether these spots are actin-like positioning patterns remains to be determined.

CAPs are well conserved in eukaryotes from yeast to mammals (Hubberstey and Mottillo 2002). The Cap1 protein in $U$. virens has typical structural characteristics

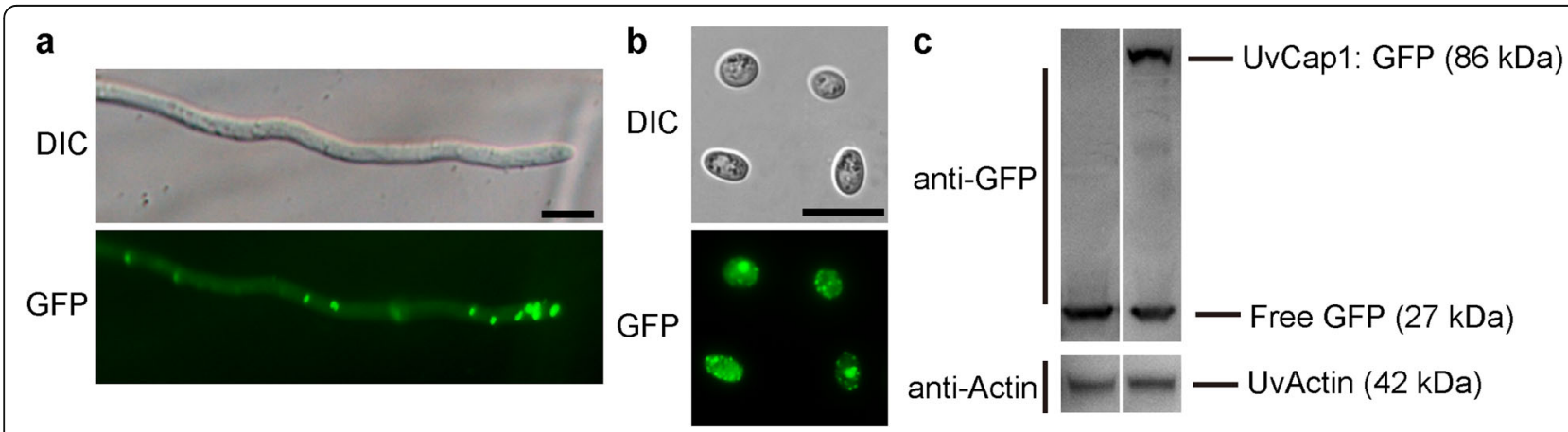

Fig. 8 Subcellular localization of UvCap1 in U. virens. a Location pattern of UvCap1 in the hyphae of U. virens. Bar, $10 \mu \mathrm{m}$. $\mathbf{b}$ Location pattern of UvCap1 in the conidia of U. virens. Bar, $10 \mu \mathrm{m}$. c Verification of UVCap1:GFP transformant by western blot using anti-GFP antibody 
of CAPs (Fig. 1a). In S. cerevisiae, the conserved Nterminal and C-terminal ends of CAPs interact with adenylate cyclase and agonist protein, respectively (Gerst et al. 1991; Freeman et al. 1995; Paavilainen et al. 2004). Our results also showed that the C-terminal region of UvAc1 interacted with UvCap1 in $U$. virens (Fig. 6). Adenylyl cyclase is a key component of the cAMP signaling pathway, and its function is to maintain the intracellular cAMP level and to participate in the proper infection morphogenesis in many pathogens (Choi and Dean 1997). The localization of adenylate cyclase is slightly different in mammals and yeast. In mammalian cells, adenylate cyclase is a transmembrane protein (Taussig and Gilman 1995), while in budding yeast, it is a peripheral membrane protein (Mitts et al. 1990; Huang et al. 1997).

The binding of CAPs to adenylate cyclase is important in regulating the post-translational modification of Ras2, which in turn is critical for the Ras-dependent activation of adenylate cyclase (Shima et al. 1997). Ras proteins are small GTP-binding proteins that recruit effectors to the cytoplasm membrane, and the activation of Ras requires Ras GTP-binding protein (RasGAP) (Shima et al. 2000; Wennerberg et al. 2005). In yeast, Ira1/2 (Ras GTPase activating protein) induces the GTPase activity of Ras1/ 2 , leading to the activation of adenylate cyclase, meanwhile promoting the synthesis of cAMP (Tanaka et al. 1991). The disruption of the IRA1 gene leads to the accumulation of a large amount of adenylate cyclase in the cytoplasm (Mitts et al. 1991). In U. virens, there is no interaction between UvCap1 and UvGap1 (unpublished data), but UvCap1 interacted with UvRas1 and UvRas2 (Fig. 6). The interaction of UvCap1 with two Ras proteins and UvAc1 may also play an important role in the activation of UvAc1.

The adaptor protein Ste50 interacts with multiple upstream components to activate the MAP kinase cascade in M. oryzae (Park et al. 2006). In S. cerevisiae, Ste50 interacts with Ste11 and is involved in the cell wall integrity in vegetative cells (Jansen et al. 2001; Ramezani-Rad 2003; Kwan et al. 2006). In Schizosaccharomyces pombe and $U$. maydis, Ste4 and Ubc2 (homologous to Ste50 in S. cerevisiae) act directly upstream of the MAP kinase cascade and are involved in mating and other developmental processes (Barr et al. 1996; Mayorga and Gold 2001). Our study showed that UvCap1 also interacted with Uvste50 in $U$. virens (Fig. 6). UvCap1 may has an important relationship with MAPK signaling pathways to affect the development and infection process of $U$. virens.

Rice false smut has become one of the most important panicle diseases of rice in recent years. M. oryzae is also a filamentous ascus fungus that infects rice. The Cap1 proteins showed many similar functions in these two pathomycetes. Mycelial growth and conidiation were both reduced in the CAP1 mutants of $U$. virens (Fig. 2) and M. oryzae (Zhou et al. 2012). CAP1 regulates the appressoria formation and invasive growth in $M$. oryzae (Zhou et al. 2012). Although $U$. virens does not form a special appressorium, the expansion of infection hyphae was influenced by UvCap1 in this fungus (Fig. 3). As is the case in $M$. oryzae, the intracellular cAMP level in the CAP1 deletion mutant of $U$. virens was reduced compared with that in the wild-type strain (Fig. 7). Previous study demonstrated that deletion of CAP1 suppresses the effects of RAS2 ${ }^{\mathrm{DA}}$ on appressoria formation in $M$. oryzae (Zhou et al. 2012). In this study, we found that UvCap1 interacted with UvRas2 in $U$. virens (Fig. 6). The subcelluar localization of UvCap1 in hyphae was similar to that of Cap1 in M. oryzae, and GFP-tagged UvCap1 was mainly localized in the apical regions of hyphae (Fig. 8).

In summary, we analyzed the function of $U \nu C A P 1$ in the development and pathogenicity of $U$. virens. Further characterization of the functional relationships among UvCap1, UvAc1, Ras proteins and UvSte50 will provide valuable information to better understand the role of UvCap1 during the infection process of the rice false smut fungus.

\section{Conclusions}

We identified a cyclase-associated protein UvCap1, which showed a high expression level during the early infection process stage of $U$. virens. The deletion of $U \nu C A P 1$ led to defects in mycelial growth, conidial production and pathogenicity. $\Delta U \nu c a p 1$ exhibited more sensitive to sorbitol and $\mathrm{H}_{2} \mathrm{O}_{2}$ stresses. The intracellular cAMP level was significantly reduced in $\Delta U v$ cap 1 compared with the wild-type strain. Yeast two-hybrid assay showed UvCap1 interacted with UvAc1, UvRas1, UvRas2 and UvSte50. Taken together, UvCap1 functions as a component of the cAMP signaling pathway, interacting with UvAc1, UvRas1, UvRas2 and UvSte50 to regulate the develpoment and pathogenicity of $U$. virens. Further work should focus on the role of UvCap1 in the cAMP signaling pathway and the relationship of UvCap1 with the PMKA signaling pathway during the infection process of the rice false smut fungus.

\section{Methods}

\section{Strains and culture conditions}

The wild-type strain $\mathrm{P}-1$ of $U$. virens was used as the starting strain for subsequent strain construction; P-1 and the derivative strains were stored in $20-30 \%$ glycerol solution at $-70{ }^{\circ} \mathrm{C}$. The strains were cultured on potato sucrose agar (PSA) medium $(200 \mathrm{~g} / \mathrm{L}$ potato, $20 \mathrm{~g} / \mathrm{L}$ sucrose, $15 \mathrm{~g} / \mathrm{L}$ agar) or TB3 medium $(3 \mathrm{~g} / \mathrm{L}$ yeast extract, $3 \mathrm{~g} / \mathrm{L}$ acid hydrolyzed casein, $20 \mathrm{~g} / \mathrm{L}$ sucrose) at 
$28^{\circ} \mathrm{C}$ in the dark for $10-20$ days (Tsukui et al. 2015). The rice cultivar Liangyoupeijiu, which is susceptible to strain $\mathrm{P}-1$, was used in the inoculation experiments $(\mathrm{Yu}$ et al. 2019). Yeast strain Y2HGold was cultured on YPDA medium $(10 \mathrm{~g} / \mathrm{L}$ yeast extract, $20 \mathrm{~g} / \mathrm{L}$ peptone, 20 $\mathrm{g} / \mathrm{L}$ glucose, $0.3 \mathrm{~g} / \mathrm{L}$ adenine hemisulfate and $20 \mathrm{~g} / \mathrm{L}$ agar) at $30^{\circ} \mathrm{C}$.

\section{Phylogenetic analysis of CAP homologous proteins}

All the homologous protein sequences of CAP in different fungi were obtained from the NCBI database and their accession numbers are shown as below: Ustilago maydis (XP 011386706.1), Cryptococcus neoformans (XP 0120485 42.1), Saccharomyces cerevisiae (PTN15174.1), Aspergillus oryzae (XP_001727621.1), Botrytis cinerea (XP_02454795 6.1), Neurospora crassa (XP_962678.3), Magnaporthe oryzae (MGG_01722), Colletotrichum orbiculare (TDZ2501 2.1), Colletotrichum gloeosporioides (KAF3811478.1), Verticillium longisporum (CRK25305.1), Verticillium longisporum (CRK26284.1), Beauveria bassiana (KGQ04943.1), Cordyceps javanica (TQV96574.1), Neonectria ditissima (KPM35571.1), Fusarium graminearum (XP_011317774.1), Fusarium fujikuroi (SCV37630.1), Fusarium oxysporum (SCO81237.1), Trichoderma harzianum (PNP52737.1), Trichoderma guizhouense (OPB37971.1), Trichoderma lentiforme (KAF3072262.1), Tolypocladium ophioglossoides (KND86868.1), Purpureocillium lilacinum (OAQ86548.1), Drechmeria coniospora (ODA78517.1), Hirsutella minnesotensis (KJZ78123.1), Claviceps purpurea (CCE30517.1), Ustilaginoidea virens (KDB15885.1), Pochonia chlamydosporia (RZR68491.1), Metarhizium guizhouense (KID907 09.1), Metarhizium robertsii (EXV04750.1), Metarhizium anisopliae (KAF5133669.1). A neighbor-joining tree based on the above sequences was built using the Phylogeny.fr platform as described previously (Dereeper et al. 2008) with 1000 bootstrap repeats for distance estimation.

\section{Construction of the UvCAP1 deletion mutant and its complemented strain}

Targeted deletion mutants of the UvCAP1 gene were obtained with gene replacement strategy assisted with CRISPR-Cas9 system. First, we created a homologous recombination construct pMD19-UvCAP1 by inserting the $H Y G$ cassette between the two flanking sequences of the $U \nu C A P 1$ gene. The 1025-bp upstream and 1104-bp downstream flanking sequences of $U \nu C A P 1$ were amplified with primer pairs $1 F / 2 \mathrm{R}$ and $3 \mathrm{~F} / 4 \mathrm{R}$, respectively (Additional file 2: Table S1). The up- and downstream flanking sequences and HYG cassette were cloned to TVector pMD19 (simple) (TaKaRa, Japan) using a ClonExpress MultiS One Step Cloning Kit (Vazyme, Nanjing).

Then the gRNA designer program was used to design $U \nu C A P 1$-gRNA spacers, and the Cas9 off program was used to screen the high-score spacer to minimize potential off-target effects in the genome (Doench et al. 2014; Guo et al. 2014). The sense and antisense strands of UvCAP1-gRNA spacer (Additional file 2: Table S1) were synthesized and annealed to generate doublestranded gRNA spacers (Arazoe et al. 2015; Liang et al. 2018). Then the double-stranded gRNA spacers were cloned to the two BsmBI sites of pmCas9:tRp-gRNA (Liang et al. 2018) using a ClonExpress II One Step Cloning Kit (Vazyme, Nanjing). The resulting construct was confirmed by sequencing.

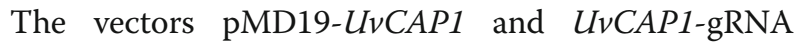
were co-transformed into protoplasts of the wild-type strain P-1 using the PEG-mediated method as described previously (Liang et al. 2018). Hygromycin-resistant transformants were screened for deletion of $U \nu C A P 1$ by PCR with primers 5F/6R (Additional file 2: Table S1). Overlapping PCR with primers $7 F / 8 R$ and $9 F / 10 R$ was used to detect whether $U \nu C A P 1$ was replaced by the $H Y G$ cassette. The $\triangle U v$ vap 1 mutants were verified by sequencing analysis (Additional file 2: Table S1).

For complementation assays, the $U_{\nu} C A P 1$ gene, along with 1025-bp upstream and 365-bp downstream sequences was amplified with primers UvCAP1-comF/comR (Additional file 2: Table S1) and inserted into the pKO1NEO (G-418 resistance) vector. Then the construct was transformed into $\Delta U v c a p 1$ (\#11) using the Agrobacteriummediated transformation (ATMT) method (Lv et al. 2016). The resulting transformants were first screened by recovery of growth defects, followed by RT-PCR amplification, and verified by fully restored phenotype characterization.

\section{Subcellular location of UvCap1}

To construct the subcellular location strain UvCap1: GFP, we amplified 1955 bp coding sequence of $U \nu C A P 1$ with primers $U \nu C A P 1-G F P F / G F P R$ (Additional file 2: Table S1). The resulting fragment was cloned into the $B a m H I$ and SmaI sites of vector pKD2-GFP and then transformed into the wild-type strain P-1 by ATMT as described previously ( $\mathrm{Lv}$ et al. 2016). G-418-resistant transformants were screened for further fluorescence microscopic observation.

\section{Phenotypic analysis of $U$. virens strains}

In the assays for mycelial growth of $U$. virens strains, the mycelia of the wild-type strain P-1, the $\Delta U v \operatorname{cap} 1$ (\#11, \#14) mutant and the complemented Uvcap1-c (\#1) were ground with a tissue blender (Waring Commercial Blender 8011S, USA) and diluted with potato sucrose broth (PSB), then individually spread evenly on PSA medium plates, and cultured at $28^{\circ} \mathrm{C}$. A mycelial block $(5 \mathrm{~mm}$ in diameter) cut from the margin of 5-day-old colony was inoculated on the center of a PSA or TB3 medium plate at $28^{\circ} \mathrm{C}$ for 20 days with 5 replicates for each group (Yu et al. 2019; Yong et al. 2020). Colony 
diameters were measured using the cross-measurement method.

In the conidiation assays, the same method as abovementioned was used to obtain mycelial blocks. Three mycelial blocks were transferred into $50 \mathrm{~mL}$ of YT $(1 \mathrm{~g} / \mathrm{L}$ yeast extract, $1 \mathrm{~g} / \mathrm{L}$ tryptone and $1 \mathrm{~g} / \mathrm{L}$ glucose) liquid medium and incubated with shaking $(150 \mathrm{rpm})$ at $28^{\circ} \mathrm{C}$ for 6 days. The number of conidia was recorded under a microscope using a hemocytometer. All the experiments were performed three times with three replicates.

\section{Plant infection assays of $U$. virens strains}

To detect if UvCap1 is involved in the infection process of $U$. virens, the susceptible rice variety Liangyoupeijiu was inoculated as described previously (Tang et al. 2013; $\mathrm{Yu}$ et al. 2015). The wild-type strain P-1, the $\Delta U v$ cap 1 (\#11) mutant and its complemented Uvcap1-c (\#1) were cultured in PSB with shaking at $150 \mathrm{rpm}, 28^{\circ} \mathrm{C}$ for 7 days. A tissue blender (Waring Commercial Blender 8011S, USA) was used for the preparation of a mixture of hyphae and conidia, and the conidia were diluted to a concentration of $1 \times 10^{6}$ conidia/mL with PSB. About 57 days before heading, $1-2 \mathrm{~mL}$ of hyphae and conidia suspensions were injected into the panicles of rice plants using sterilized syringes. Inoculated rice plants were cultured in a humid environment with a water spray system and the number of rice false smut balls per panicle were counted at $30 \mathrm{dpi}$ (Hu et al. 2014; Yong et al. 2020). The expansion of infection hyphae inside the spikelets of the wild-type strain P-1, the $\Delta U v$ cap1 (\#11) mutant and its complemented Uvcap1-c (\#1) were observed at 10, 14 and 18 dpi. GFP-tagged strains of $U$. virens were also constructed to further ascertain if UvCap1 is involved in the infection process. The binary vector $\mathrm{pKD} 2-\mathrm{GFP}$ was transformed into P-1, $\Delta$ Uvcap1 (\#11) and Uvcap1-c (\#1) by ATMT as described previously (Lv et al. 2016). The expansion of infection hyphae inside the spikelets of these GFP-tagged strains was observed at $10 \mathrm{dpi}$ under the stereo fluorescence microscope (Olympus IX71, Japan). The test was repeated three times in total.

\section{Stress response assays of $U$. virens strains}

In the stress response assays, the same method as abovementioned was used to obtain mycelial blocks. A mycelial block ( $5 \mathrm{~mm}$ in diameter) cut from the margin of 5-dayold colony was inoculated on the center of a PSA medium plate or PSA supplemented with different concentrations of stress agents, including $0.5 \mathrm{M} \mathrm{NaCl}, 0.6 \mathrm{M}$ sorbitol, $500 \mu \mathrm{g} / \mathrm{mL}$ CFW, $100 \mu \mathrm{g} / \mathrm{mL}$ Congo red, $0.05 \%$ SDS and $0.05 \% \mathrm{H}_{2} \mathrm{O}_{2}$. The plates were incubated in $28^{\circ} \mathrm{C}$ for 20 days, with five replicates for each group (Yu et al. 2019; Yong et al. 2020). Colony diameters were measured using the cross-measurement method. Inhibition rates were calculated as described previously (Xie et al. 2019; Yong et al. 2020).

\section{RT-qPCR analysis of the expression level of UvCAP1}

Rice spikelets were collected at $0,1,2,3,5,7$ and 14 dpi. RNA was extracted using an RNA extraction kit (BioTeKe, China) and cDNA reverse transcription was performed with the PrimeScript ${ }^{\mathrm{tw}}$ RT reagent Kit with gDNA Eraser (TaKaRa, Japan) as previously described (Yong et al. 2020). qPCR was performed in an ABI Q6 Real-Time System with primers $U \nu C A P 1-\mathrm{qF} / \mathrm{qR}$ (Additional file 2: Table S1). TB Green ${ }^{\circ}$ Premix Ex Taq ${ }^{\mathrm{Tm}}$ II (Tli RNaseH Plus) (TaKaRa, Japan) was used to evaluate the relative abundance of target gene transcripts, and the average threshold cycle $(\mathrm{Ct})$ was normalized to that of the TUBULIN gene (TUBULIN-qF/-qR) (Additional file 2: Table S1).

\section{Yeast two-hybrid assay}

Protein-protein interactions were performed using the yeast two-hybrid system (Clontech, USA). The ORF regions of $U \nu C A P 1$ was amplified from the CDNA of the wild-type strain $\mathrm{P}-1$ with primers $U \nu C A P 1-\mathrm{BDF} / \mathrm{BDR}$ (Additional file 2: Table S1) and cloned into pGBKT7 vector using the ClonExpress II One Step Cloning Kit (Vazyme, China). The ORF regions of $U v R A S 1, U_{v} R A S 2$ and UvSTE50 were individually cloned into the pGADT7 vector to obtain prey constructs. Then the resulting bait and prey constructs were co-transformed into yeast strain Y2HGold. The transformants were grown on SD/-Leu/Trp, SD/-His/-Leu/-Trp and SD/-Ade/-His/-Leu/-Trp medium for $3-5$ days at $30^{\circ} \mathrm{C}$.

\section{Abbreviations \\ ATMT: Agrobacterium-mediated transformation; CAPs: Cyclase-associated proteins; CFW: Calcofluor white; CLSM: Confocal laser scanning microscope; CR: Congo red; dpi: Days post inoculation; HYG: Hygromycin resistance gene; GFP: Green fluorescent protein; NCBI: National Center for Biotechnology Information; ORF: Open reading frame; PSA: Potato sucrose agar; PSB: Potato sucrose broth; RT-qPCR: Reverse transcription quantitative PCR}

\section{Supplementary Information}

The online version contains supplementary material available at https://doi. org/10.1186/s42483-021-00083-0

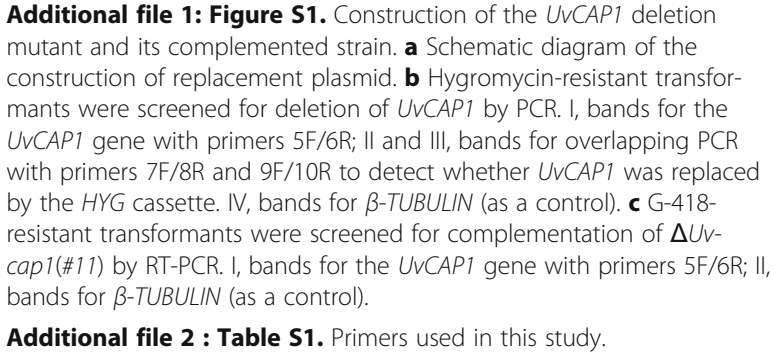

Additional file 1: Figure S1. Construction of the UVCAP1 deletion mutant and its complemented strain. a Schematic diagram of the construction of replacement plasmid. b Hygromycin-resistant transformants were screened for deletion of UVCAP1 by PCR. I, bands for the UVCAP1 gene with primers 5F/6R; II and III, bands for overlapping PCR with primers 7F/8R and 9F/10R to detect whether UVCAP1 was replaced by the HYG cassette. IV, bands for $\beta$-TUBULIN (as a control). c G-418resistant transformants were screened for complementation of $\Delta U_{V}$ cap 1(\#11) by RT-PCR. I, bands for the UVCAP1 gene with primers 5F/6R; ॥, bands for $\beta$-TUBULIN (as a control).

Additional file $\mathbf{2}$ : Table S1. Primers used in this study. 


\section{Authors' contributions}

HJC conceived the study and wrote the manuscript. JJZ and HJC carried out the experiments. MLY, MNY, TQS, JJY and XYP contributed to the materials and analysis procedure. YFL revised the manuscript critically. All authors have read and approved the final manuscript.

\section{Funding}

This work was supported by the National Natural Science Foundation of China (31901838) and Natural Science Foundation of Jiangsu Province (BK20180296 and BK20160588).

\section{Availability of data and materials}

No applicable.

\section{Declarations}

Ethics approval and consent to participate

No applicable.

\section{Consent for publication}

No applicable.

\section{Competing interests}

The authors declare that they have no competing interests.

Received: 22 October 2020 Accepted: 2 March 2021

Published online: 15 March 2021

\section{References}

Adachi K, Hamer JE. Divergent CAMP signaling pathways regulate growth and pathogenesis in the rice blast fungus Magnaporthe grisea. Plant Cell. 1998;10: $1361-73$

Arazoe T, Miyoshi K, Yamato T, Ogawa T, Ohsato S, Arie T, et al. Tailor-made CRIS $\mathrm{PR} / \mathrm{Cas}$ system for highly efficient targeted gene replacement in the rice blast fungus. Biotechnol Bioeng. 2015;112:2543-9.

Bahn YS, Hicks JK, Giles SS, Cox GM, Heitman J. A denylyl cyclase-associated protein Aca1 regulates virulence and differentiation of Cryptococcus neoformans via the cyclic AMP protein kinase A cascade. Eukaryot Cell. 2004; 3:1476-91.

Bahn YS, Sundstrom P. CAP1, an adenylate cyclase-associated protein gene, regulates bud-hypha transitions, filamentous growth, and cyclic AMP levels and is required for virulence of Candida albicans. J Bacteriol. 2001; 183:3211-23.

Barr MM, Tu H, Van Aelst L, Wigler M. Identification of Ste4 as a potential regulator of Byr2 in the sexual response pathway of Schizosaccharomyces pombe. Mol Cell Biol. 1996;16:5597-603.

Bertling E, Hotulainen P, Mattila PK, Matilainen T, Salminen M, Lappalainen P. Cyclase-associated protein 1 (CAP1) promotes cofilin-induced actin dynamics in mammalian nonmuscle cells. Mol Biol Cell. 2004;15:2324-34.

Choi W, Dean RA. The adenylate cyclase gene MACl of Magnaporthe grisea controls appressorium formation and other aspects of growth and development. Plant Cell. 1997;9:1973-83.

Dereeper A, Guignon V, Blanc G, Audic S, Buffet S, Chevent F, et al. Phylogeny.fr: robust phylogenetic analysis for the non-specialist. Nucleic Acids Res. 2008; 36(web server issue):W465-9.

Doench JG, Hartenian E, Graham DB, Tothova Z, Hegde M, Smith I, et al. Rational design of highly active sgRNAs for CRISPR-Cas9-mediated gene inactivation. Nat Biotechnol. 2014:32:1262-7.

Field J, Vojtek A, Ballester R, Bolger G, Colicelli J, Ferguson K, et al. Cloning and characterization of CAP, the Saccharomyces cerevisiae gene encoding the 70 Kd adenylyl cyclase associated protein. Cell. 1990;61:319-27.

Freeman NL, Chen Z, Horenstein J, Weber A, Field J. An actin monomer bindingactivity localizes to the carboxyl-terminal half of the Saccharomyces-cerevisiae cyclase-associated protein. J Biol Chem. 1995;270:5680-5.

Gerst JE, Ferguson K, Vojtek A, Wigler M, Field J. Cap is a bifunctional component of the Saccharomyces cerevisiae adenylyl cyclase complex. Mol Cell Biol. 1991; 11:1248-57.

Gottwald U, Brokamp R, Karakesisoglou I, Schleicher M, Noegel AA. Identification of a cyclase-associated protein (CAP) homologue in Dictyostelium discoideum and characterization of its interaction with actin. Mol Biol Cell. 1996;7:261-72.
Guo W, Gao Y, Yu Z, Xiao Y, Zhang Z, Zhang H. The adenylate cyclase UvAc1 and phosphodiesterase UvPdeH control the intracellular cAMP level, development, and pathogenicity of the rice false smut fungus Ustilaginoidea virens. Fungal Genet Biol. 2019;129:65-73.

Guo XG, Zhang TJ, Hu Z, Zhang YQ, Shi ZY, Wang QH, et al. Efficient RNA/ Cas9-mediated genome editing in Xenopus tropicalis. Development. 2014; 141:707-14.

Hu ML, Luo LX, Wang S, Liu YF, Li JQ. Infection processes of Ustilaginoided virens during artificial inoculation of rice panicles. Eur J Plant Pathol. 2014;139:67-77.

Huang CF, Hepler JR, Chen LT, Gilman AG, Anderson RGW, Mumby SM. Organization of $\mathrm{G}$ proteins and adenylyl cyclase at the plasma membrane. Mol Biol Cell. 1997:8:2365-78.

Hubberstey AV, Mottillo EP. Cyclase-associated proteins: CAPacity for linking signal transduction and actin polymerization. FASEB J. 2002;16(6):487-99.

Jansen G, Buhring F, Hollenberg CP, Rad MR. Mutations in the SAM domain of STE50 differentially influence the MAPH-mediated pathways for mating, filamentous growth and osmotolerance in Saccharomyces cerevisiae. Mol Gen Genomics. 2001:265:102-17.

Kang SH, Khang CH, Lee YH. Regulation of CAMP-dependent protein kinase during appressorium formation in Magnaporthe grisea. FEMS Microbiol Lett. 1999;170:419-23.

Kawamukai M, Gerst J, Field J, Riggs M, Rodgers L, Wigler M, et al. Genetic and biochemical-analysis of the adenylyl cyclase-associated protein, Cap, in Schizosaccharomyces pombe. Mol Biol Cell. 1992;3:167-80.

Kwan JJ, Warner N, Maini J, Tung KWC, Zakaria H, Pawson T, et al. Saccharomyces cerevisiae Ste50 binds the MAPKKK Ste11 through a head-to-tail SAM domain interaction. J Mol Biol. 2006;356:142-54.

Liang YF, Han Y, Wang CF, Jiang C, Xu JR. Targeted deletion of the USTA and UVSLT2 genes efficiently in Ustilaginoidea virens with the CRISPR-Cas9 system. Front Plant Sci. 2018:9:699.

Lv B, Zheng L, Liu H, Tang J, Hsiang T, Huang J. Use of random T-DNA mutagenesis in identification of gene UVPRO1, a regulator of conidiation, stress response, and virulence in Ustilaginoidea virens. Front Microbiol. 2016;7:2086

Mayorga ME, Gold SE. The ubc2 gene of Ustilago maydis encodes a putative novel adaptor protein required for filamentous growth, pheromone response and virulence. Mol Microbiol. 2001:41:1365-79.

Mintzer KA, Field J. Interactions between adenylyl cyclase, cap and ras from Saccharomyces cerevisiae. Cell Signal. 1994;6:681-94.

Mitts MR, Bradshawrouse J, Heideman W. Interactions between adenylate-cyclase and the yeast GTPase-activating protein Ira1. Mol Cell Biol. 1991;11:4591-8.

Mitts MR, Grant DB, Heideman W. Adenylate cyclase in Saccharomyces cerevisiae is a peripheral membrane protein. Mol Cell Biol. 1990;10:3873-83.

Noegel AA, Rivero F, Albrecht R, Janssen KP, Kohler J, Parent CA, et al. Assessing the role of the ASP56/CAP homologue of Dictyostelium discoideum and the requirements for subcellular localization. J Cell Sci. 1999;112:3195-203.

Paavilainen VO, Bertling E, Falck S, Lappalainen P. Regulation of cytoskeletal dynamics by actin-monomer-binding proteins. Trends Cell Biol. 2004;14: $386-94$.

Park G, Xue C, Zhao X, Kim Y, Orbach M, Xu JR. Multiple upstream signals converge on the adaptor protein Mst50 in Magnaporthe grisea. Plant Cell. 2006;18:2822-35.

Quintero-Monzon O, Jonasson EM, Bertling E, Talarico L, Chaudhry F, Sihvo M, et al. Reconstitution and dissection of the 600-kDa Srv2/CAP complex roles for oligomerization and cofilin-actin binding in driving actin turnover. J Biol Chem. 2009:284:10923-34.

Ramezani-Rad M. The role of adaptor protein Ste50-dependent regulation of the MAPKKK Ste11 in multiple signalling pathways of yeast. Curr Genet. 2003;43: $161-70$.

Rocha CRC, Schroppel K, Harcus D, Marcil A, Dignard D, Taylor BN, et al. Signaling through adenylyl cyclase is essential for hyphal growth and virulence in the pathogenic fungus Candida albicans. Mol Biol Cell. 2001;12:3631-43.

Shima F, Okada T, Kido M, Sen H, Tanaka Y, Tamada M, et al. Association of yeast adenylyl cyclase with cyclase-associated protein CAP forms a second Rasbinding site which mediates its Ras-dependent activation. Mol Cell Biol. 2000; 20:26-33.

Shima F, Yamawaki-Kataoka Y, Yanagihara C, Tamada M, Okada T, Kariya K, et al. Effect of association with adenylyl cyclase-associated protein on the interaction of yeast adenylyl cyclase with Ras protein. Mol Cell Biol. 1997;17: $1057-64$. 
Song JH, Wei W, Lv B, Lin Y, Yin WX, Peng YL, et al. Rice false smut fungus hijacks the rice nutrients supply by blocking and mimicking the fertilization of rice ovary. Environ Microbiol. 2016;18:3840-9.

Sun WX, Fan J, Fang AF, Li YJ, Tariqjaveed M, Li DY, et al. Ustilaginoidea virens: insights into an emerging rice pathogen. Annu Rev Phytopathol. 2020;58: 363-85.

Takach JE, Gold SE. Identification and characterization of Cap1, the adenylate cyclase-associated protein (CAP) ortholog in Ustilago maydis. Physiol Mol Plant Pathol. 2010;75(1-2):30-7.

Talbot NJ. On the trail of a cereal killer: exploring the biology of Magnaporthe grisea. Annu Rev Microbiol. 2003;57:177-202.

Tanaka K, Lin BK, Wood DR, Tamanoi F. Ira2, an upstream negative regulator of Ras in yeast, is a Ras GTPase-activating protein. Proc Natl Acad Sci U S A. 1991;88:468-72.

Tang YX, Jin J, Hu DW, Yong ML, Xu Y, He LP. Elucidation of the infection process of Ustilaginoidea virens (teleomorph: Villosiclava virens) in rice spikelets. Plant Pathol. 2013;62:1-8.

Taussig R, Gilman AG. Mammalian membrane-bound adenylyl cyclases. J Biol Chem. 1995;270:1-4.

Tsukui T, Nagano N, Umemura M, Kumagai T, Terai G, Machida M, et al. Ustiloxins, fungal cyclic peptides, are ribosomally synthesized in Ustilaginoidea virens. Bioinformatics. 2015:31:981-5.

Wang CH, Zhou GL, Vedantam S, Li P, Field J. Mitochondrial shuttling of CAP1 promotes actin- and cofilin-dependent apoptosis. J Cell Sci. 2008; 121:2913-20

Wennerberg K, Rossman KL, Der CJ. The Ras superfamily at a glance. J Cell Sci. 2005;118:843-6.

Xie SL, Wang YF, Wei W, Li CY, Liu Y, Qu JS, et al. The Bax inhibitor UvBl-1, a negative regulator of mycelial growth and conidiation, mediates stress response and is critical for pathogenicity of the rice false smut fungus Ustilaginoidea virens. Curr Genet. 2019;65:1185-97.

Yong ML, Yu JJ, Pan XY, Yu MN, Cao HJ, Qi ZQ, et al. MAT1-1-3, a mating type gene in the Villosiclava virens, is required for fruiting bodies and sclerotia formation, asexual development and pathogenicity. Front Microbiol. 2020;11:1337.

Yu J, Wang C, Palmieri SJ, Haarer BK, Field J. A cytoskeletal localizing domain in the cyclase-associated protein, CAP/Srv2p, regulates access to a distant SH3binding site. J Biol Chem. 1999;274:19985-91.

Yu JJ, Sun WX, Yu MN, Yin XL, Meng XK, Zhao J, et al. Characterization of matingtype loci in rice false smut fungus Villosiclava virens. FEMS Microbiol Lett. 2015;362:fnv014.

Yu JJ, Yu MN, Song TQ, Cao HJ, Pan XY, Yong ML, et al. A homeobox transcription factor UVHOX2 regulates chlamydospore formation, conidiogenesis, and pathogenicity in Ustilaginoidea virens. Front Microbiol. 2019;10:1071

Zheng D, Wang Y, Han Y, XU JR, Wang C. UVHOG1 is important for hypha growth and stress responses in the rice false smut fungus Ustilaginoidea virens. Sci Rep. 2016;6:24824.

Zhou XY, Zhang HF, Li GT, Shaw B, XU JR. The cyclase-associated protein Cap1 is important for proper regulation of infection-related morphogenesis in Magnaporthe oryzae. PLoS Pathog. 2012;8:e1002911.

Zhou YL, Pan YJ, Xie XW, Zhu LH, Xu JL, Wang S, et al. Genetic diversity of rice false smut fungus, Ustilaginoidea virens and its pronounced differentiation of populations in North China. J Phytopathol. 2008;156:559-64.

Zou H, Fang HM, Zhu Y, Wang Y. Candida albicans Cyr1, Cap1 and G-actin form a sensor/effector apparatus for activating CAMP synthesis in hyphal growth. Mol Microbiol. 2010;75:579-91.

Ready to submit your research? Choose BMC and benefit from:

- fast, convenient online submission

- thorough peer review by experienced researchers in your field

- rapid publication on acceptance

- support for research data, including large and complex data types

- gold Open Access which fosters wider collaboration and increased citations

- maximum visibility for your research: over $100 \mathrm{M}$ website views per year

At BMC, research is always in progress.

Learn more biomedcentral.com/submissions 